\title{
PROTECTING ME FROM MY DIRECTIVE \\ ENSURING APPROPRIATE SAFEGUARDS FOR ADVANCE DIRECTIVES IN DEMENTIA
}

\begin{abstract}
With one in six people over 80 now suffering from dementia, advance directives provide an important means of empowerment. Upholding directives in the context of dementia however, raises extra challenges, given the potential for the directive to conflict with an assessment of what is in the person's current best interests. Given the profound harm that tying a person with dementia to their previous wishes can do, it is essential that we have sufficient safeguards in place to ensure that we only uphold such directives where we can be sure they are truly autonomous and are intended to apply to the situation at hand- safeguards which are at present, severely lacking.
\end{abstract}

This paper will consider various mechanisms by which safeguards can be built into the legal regime to ensure that the original decision is autonomous, including making it mandatory for the person to undergo a consultation with a healthcare professional, which would involve a contemporaneous capacity assessment. Clinicians must also be confident that the directive applies to the situation at hand. Introducing formalities, including a standardised (though not mandatory) proforma, may help to enhance specificity about when the directive is triggered, and to what treatments it relates, to enable clinicians to better assess the directive's applicability. A national registry for advance directives might also be beneficial. It will be argued that health care professionals will have to play a much greater role in the drafting and registering of advance directives, if we are to feel comfortable in upholding them.

Key words: advance decisions, advance directives, dementia, incapacity, prospective autonomy, safeguards

\section{INTRODUCTION}

Under section 24 of the Mental Capacity Act 2005, a person may, at a time at which they retain capacity, create an advance directive to refuse certain treatments. The advance directive will apply if, 'at a later time and in such circumstances as he may specify', ${ }^{1}$ the treatment in question is proposed to be carried out or continued and the person lacks capacity to consent.

\footnotetext{
${ }^{1}$ Mental Capacity Act 2005, s24.
} 
In most cases, upholding a directive will prove uncontroversial. As advance directives are usually made to refuse life-prolonging treatment, ${ }^{2}$ most people will only wish to refuse such treatment where either the treatment is required when they are in their final stages of life, or where, due to illness or accident, they have been left severely and permanently incapacitated (for example in a persistent vegetative or minimally conscious state). In such circumstances, life-sustaining treatment will often not be considered in the person's best interests, and thus following the advance directive may be unproblematic as the treatment is likely to be denied regardless of whether the directive is being followed or a best interests assessment is being made (albeit that the absence of a directive may result in the case having to go to Court for an order to be made that it is in the person's best interests ${ }^{3}$ ). Dementia however, can present a rare conflict between a previously made directive, and what the person currently wants or what the doctor believes (taking into account the person's other past and present wishes), is in their best interests. This is unlikely to be the case where the person's dementia causes them considerable distress and discomfort. Rather, the concern is with people for whom dementia does not render them distressed, in pain, or close to death; the "pleasantly demented", as Rhoden puts it. ${ }^{4}$ For these people the advance directive may not be reflective of values they now hold, or interests they now have. Although there is currently no case law on the issue, given the profound harm that tying them to their previous wishes could therefore cause, sufficient safeguards are essential to ensure that such directives are only upheld where we can be sure that they are truly autonomous and are intended to apply to the situation at hand.

Whether we ought to uphold advance directives in this context has been subject to considerable debate. ${ }^{5}$ However even for those offering the most vociferous defence of advance directives,${ }^{6}$ their moral authority stems from their respect for a person's precedent autonomy. The ethical justification offered is that a person has a right to decide, at a time at which they are still able to make an autonomous decision, how they wish to be treated when they have lost that ability. If the original decision is not

2 P. Triplett et al. 'Content of Advance Directives for individuals with advanced dementia' (2008) Journal of Aging and Health 20:583-596.

${ }^{3}$ As cases such as Aintree University Hospitals NHS Foundation Trust v James [2013] UKSC 67 demonstrate.

${ }^{4}$ N. Rhoden, 'The Limits of Legal Objectivity' (1990) North Carolina Law Review 68:845-65.

${ }^{5}$ For a more detailed discussion, see R. Dworkin, Life's Dominion (Harper Collins, 1993), 179-217; R. Dworkin, 'Autonomy and the demented self', The Millbank Quarterly 1986;64(2): 4-16; R. Dresser, 'Dworkin on Dementia' (1995) Hastings Center Report 25(6), 32; D. Parfit, Reasons and Persons (OUP, 1986), 204-209; B.A. Rich, 'Prospective Autonomy and Critical Interests: A Narrative Defense of the Moral Authority of Advance Directives' (1997) 6 Cambridge Quarterly of Healthcare Ethics 138; H. Kuhse, 'Some Reflections on the Problem of Advance Directives, Personhood, and Personal Identity' (1999) Kennedy Institute of Ethics Journal 9.4 347-364; J. Wall, 'Being and Being Lost' in C. Foster, J. Herring and I. Doron, The Law and Ethics of Dementia (Hart Publishing, 2014); C. Korsgard, 'Personal Identity and the Unity of Agency: A Kantian Response to Parfit' (1989) Philosophy and Public Affairs 18(2)101-132;; A. Jaworska, "Respecting the Margins of Agency: Alzheimer's Patients and the Capacity to Value," Philosophy \& Public Affairs 28, no. 2 (1999):105-138.

${ }^{6}$ R. Dworkin, Life's Dominion (Harper Collins, 1993), 179-217; R. Dworkin, 'Autonomy and the demented self', The Millbank Quarterly 1986;64(2): 4-16. 
therefore autonomous at the time it was made, the justification for upholding them dissipates: the directive loses its moral authority. Given this, it is perhaps surprising that there are so few legal safeguards in place to ensure that advance decisions are autonomous at the time of drafting. In the absence of these, we cannot be justified in upholding an advance directive where doing so may be deeply harmful to the person.

Despite the potentially widespread risk of this problem (with one in six people over 80 now suffering from dementia ${ }^{7}$ ), the legal framework surrounding advance directives is yet to receive much attention in the literature. This paper will consider various mechanisms by which safeguards can be built into the legal regime to ensure that an advance directive is autonomous, including making it mandatory for the person to undergo a consultation with a healthcare professional, which would involve a contemporaneous capacity assessment. Clinicians must also be confident that the directive is intended to apply to the situation at hand, necessitating a degree of precision in the drafting of it. Introducing formalities, including a standardised (though not mandatory) proforma, may help to enhance specificity about when the directive is triggered, and to what treatments it relates, to enable clinicians to better assess whether the directive was intended to apply in the current circumstances. It will be argued that healthcare professionals will have to play a much greater role in the drafting and registering of advance directives, if we are to feel comfortable in upholding them.

A more fundamental problem however remains. Given the dramatic changes of character that dementia can provoke, this raises the question of whether it is still right to uphold a directive where a person's values, priorities or lifestyle have changed so significantly since drafting the directive, that it is unclear whether the values which underpinned the decision have remained the same. While there is no way of alleviating this problem (this is an inherent difficulty with making decisions in advance), steps can be taken, for example encouraging directives to include a 'statement of values', to inform the doctor of the values underpinning the advance decision, so that they can assess whether these might have changed. Explicitly stating whether there are any circumstances which might invalidate the directive, or render it inapplicable, would also help in this regard, both for the doctor later called upon the implement the directive, and for the person drafting the directive, to help them direct and channel their thoughts and wishes.

Even where the robustness of advance directives is improved, there remains a further problem, of ensuring that the directive comes to the attention of the treating clinician at the relevant time. While placing the directive in medical records might present a cheaper, and less onerous way of recording directives, until integrated electronic health records are completed across the UK, this may not render directives

\footnotetext{
${ }^{7}$ Alzheimer's Society, 'Statistics', <www.alzheimers.org.uk/statistics> accessed 23 ${ }^{\text {rd }}$ May 2015.
} 
sufficiently accessible, and thus a national registry may be preferable if the aim of respecting a person's autonomy is to be achieved.

Enhancing the safeguards surrounding advance directives is essential, especially in the context of dementia. This will require doctors to act as 'gatekeepers' for the validity of directives, necessitating a far greater readiness to engage in discussions about end-of-life care. However it is only through ensuring the 'medical quality' of advance directives, that the law can be justified in upholding them.

\section{ETHICAL CHALLENGES POSED BY ADVANCE DIRECTIVES}

The ethical basis for upholding advance directives has been subject to much critique in the literature. ${ }^{8}$ While it is not the intention of this paper to delve further into this debate, it is clear that underpinning the defence of advance directives is the belief that directives respect, and give effect to, a person's precedent autonomy. ${ }^{9}$ As such, a directive may only be justified in so far as it represents an autonomous choice. In the absence of this the directive loses its moral authority, and therefore there can be no ethical basis for upholding it. Given the inherent nature of advance directives involves making a decision in anticipation of a whole range of possible circumstances, conditions and treatment options, a number of potential concerns may be raised about whether the choices embodied in directives can be truly autonomous, and therefore warrant being upheld.

Innumerable competing conceptions of autonomy have been advanced over the years, which emphasise differing aspects as essential to the concept. While it is not possible to outline all of these, two conceptions will be considered here for the purposes of analysing the position of the law: a minimal conception of autonomy, and a more demanding account. At its minimum, autonomy demands that a decision must be made with an understanding of its nature and consequences, and free from the coercion of others. This, as will be discussed below, is reflected in the legal test for capacity. ${ }^{10}$ In a more demanding account, autonomy requires the ability to apply the relevant facts to the values a person holds, to reach a decision that reflects, as different commentators have expressed it, their endorsed beliefs or desires, ${ }^{11}$ their underlying and enduring commitments, ${ }^{12}$ or 'the self or individuality of the person', however this is understood. ${ }^{13}$ This section will explore some of the challenges that anticipatory decisions may pose for meeting such accounts of autonomy. While these

\footnotetext{
${ }^{8}$ Supra $\mathrm{n} 5$.

9 Supra n6.

${ }^{10} \operatorname{MCA~s3(1).~}$

${ }^{11}$ A. Jaworska, 'Respecting the margins of agency: Alzheimer's patients and the capacity to value.' (1999) Philos Public Aff 28(2): 105-138.

12 A. Buchanan \& D. Brock. Deciding for Others (Cambridge: Cambridge University Press, 1989), 41.

13 O. O’Neill. Autonomy and Trust in Bioethics (Cambridge, Cambridge University Press; 2002), 34.
} 
concerns relate to the quality of advance decisions at the time of drafting, there remains a second, analytically distinct challenge posed by directives: should they continue to be upheld even in instances where the person's values or priorities have changed? It should be noted at the outset that this is not intended to suggest that advance directives should never be upheld. Rather, it is the contention of this paper that in recognition of these difficulties, the law must take steps to better safeguard the authenticity and relevancy of directives, to ensure that only those that are truly autonomous are upheld.

\section{A. Ensuring that the decision is autonomous at the time of drafting}

Even at its most limited, autonomy demands that a person understands the nature and consequences of the decision they are making. Anticipatory decisions therefore inevitably face an epistemic problem: unlike in a contemporaneous decision where the current circumstances of the individual, their condition, and the available treatment options are all known to the person, for advance decisions this information may all be unknown at the time of making it. Advance directives are also likely to apply not just to one decision, but to a number of decisions (refusing a number of different treatments in a variety of situations) thus demanding an even greater level of comprehension, if the implications of each of these is to have been properly considered.

For a person's choice to reflect their autonomous will, that decision must also only be applied in the circumstances that they intended. While this may seem a trite observation, this can cause particular problems in the context of directives which often do not possess the requisite degree of specificity to indicate exactly when the directive was intended by the author to apply. ${ }^{14}$ Particularly in the context of dementia, directives often relate to 'withholding life-sustaining treatment', or similar wording. Many things may fall within the definition of 'life-sustaining treatment' however. While artificial nutrition and hydration might fall clearly within the sort of treatment that the person anticipated when writing the directive, for those advanced in age, something as simple as antibiotics for a chest infection could be integral to sustaining and prolonging life. Where directives are framed in such vague terms, it is hard to know whether this considerably smaller intervention is also the sort of treatment which the person intended to refuse, and whether there are forms of palliative care that might still be acceptable to the individual. Indeed the lack of clarity in this context might not only apply to what treatment is covered by the directive, but also to when the directive is intended to be triggered. Given that dementia is a degenerative disease, there is not a definitive point at which someone 'gets dementia' or when their dementia 'becomes severe', nor is dementia represent a single disease with a defined set of symptoms. Despite this gradual process of decline, the triggering conditions of

\footnotetext{
${ }^{14}$ R. Dresser, "Dworkin on Dementia: Elegant Theory, Questionable Policy” 91995) Hastings Center Report 6.
} 
the directive are often not set out in sufficient detail to know exactly when it comes into force.

Allen Buchanan also points to a further challenge to the quality of directives at the time of drafting: the risk that the "informal safeguards" which may restrain imprudent choices in the here and now, may not extend to decisions far in the future, which are unlikely to provoke the same emotive and protective responses for those around them. ${ }^{15}$ A number of things could therefore call into question the authenticity of an advance decision at the time of drafting, and the extent to which it might be described as truly autonomous in the senses described above. It was for this reason that Buchanan concludes that "there are several morally significant asymmetries between the contemporaneous choice of a competent individual and the issuance of an advance directive to cover future decisions". ${ }^{16}$ While it may not be possible to alleviate all of these asymmetries, it is imperative that the law seeks ways to mitigate the effects of these.

\section{B. Challenges to validity on implementation}

Even where a person has the requisite degree of knowledge and understanding at the time of drafting however, a further problem remains. As the directive may have been drafted a long time in advance it is possible that it may not, at the time of implementation, continue to represent the person's values or priorities. The person may have found a religion; got married; or had children. Their lifestyle may have changed such that the condition they were painstakingly trying to avoid no longer seems so daunting; or they may have anticipated that this decision was in the interests of their loved ones, but in fact their family vehemently opposes it. Even if the decision was an endorsement of their values and beliefs at the time (and thus autonomous in even the most demanding sense), can we still be justified in upholding it if there is evidence that the decision no longer reflects the values and beliefs they held? To use an extreme example, if a Jehovah's Witness stipulates that they wish to refuse blood transfusions but then subsequently renounces their faith, would it still be right to uphold their directive, even if it had been autonomous at the time that it was made?

At the time of implementation, there is very little one can do to test or clarify any of these issues raised in this section. The person's capacity, understanding, and motivations are all, to an extent, a matter of guess-work: the doctor has no option to 'play it safe' and check, and therefore must make a potentially harmful decision for the patient with relatively little, if any, evidence of their previous state of mind. Given the clear potential therefore for advance directives to have been made without sufficient information and understanding, or to no longer reflect the wishes of the person, we should require clear evidence that the decision is autonomous and

\footnotetext{
15 A. Buchanan, 'Advance Directives and the Personal Identity Problem' (1988) Philosophy and Public Affairs 17:278-9.

16 ibid.
} 
applicable if we are to give effect to it in circumstances where it conflicts with a doctor's assessment of their current best interests. The current legal regime however, provides insufficient mechanisms by which to ascertain this important evidence.

\section{PROBLEMS WITH THE LAW'S RESPONSE}

To some extent, the law attempts to respond to these ethical challenges through its provisions in sections $24-26 \mathrm{MCA}$. As well as requiring the person to have capacity in order to create a directive, ${ }^{17}$ the Act also gives healthcare professionals a relatively wide discretion to decide not to uphold directives where they have doubts over whether the directive is valid and applicable to the situation at hand. While subsequently withdrawing a directive, ${ }^{18}$ or transferring the power of the decision to a Lasting Power of Attorney will render it invalid, ${ }^{19}$ so too may any behaviour "which is clearly inconsistent with the directive". ${ }^{20}$ A directive is not applicable meanwhile, if the treatment required is not that specified in the advance directive, ${ }^{21}$ any circumstances specified in the directive are absent, ${ }^{22}$ or "there are reasonable grounds for believing that circumstances exist which the patient did not anticipate at the time of the advance decision and which would have affected his decision had he anticipated them." ${ }^{23}$ Section 26 protects healthcare professionals from liability for treating patients when they are not "satisfied that an advance decision exists which is valid and applicable to the treatment". ${ }^{24}$ Applying these provisions raises particular problems in the dementia context however.

\section{A. Inconsistent behaviour after a loss of capacity}

To be valid, the person must not have behaved in any way that is inconsistent with the directive. While this provision may seem to capture the instances articulated above (where a person's values or priorities appear to change after the drafting of the directive) it is unclear on the face of the statute whether this is intended to cover only behaviour while the person retains capacity, or whether this may apply after losing capacity. If the latter then, clearly, the behaviour of a person with dementia could often render the directive invalid. While there has been no judicial determination of the issue, it is fiercely debated in the academic literature. Alasdair Maclean rightly observes that read alongside s24(3), which states that "P may withdraw or alter an advance decision at any time when he has capacity to do so", it may seem logical that Parliament intended the provision to be limited to behavior while competent. Moreover, as Alex Ruck Keene notes, both of the other provisions within s.25(2)

\footnotetext{
${ }^{17}$ MCA s24(1).

18 ibid s25(2)(a).

19 ibid s25(2)(b).

20 ibid s25(2)(c).

21 ibid s25(4)(a).

22 ibid s25(4)(b).

23 ibid s25(4)(c).

24 ibid s26(2).
} 
clearly relate to circumstances in which the person retains capacity (withdrawing an $\mathrm{AD}$, or creating a LPA). ${ }^{25}$ It nonetheless seems odd that the legislature should not have chosen to make this explicit, especially given multiple references to the person's capacity elsewhere in sections 24 to 26 . The Government, when responding to concerns raised by the Joint Committee on Human Rights on this issue, noted that the Bill already contained provision for an AD to be invalidated if, under clause 25(2)(c), "the person did lack capacity but had acted inconsistently with the advance decision", ${ }^{26}$ further fueling the debate, though the example then given in the Explanatory Notes to the Act, is of an act prior to the onset of incapacity. ${ }^{27}$ Nor has the judiciary been completely clear: in A Local Authority $v E^{28}$ concerning the advance directive of a woman with severe anorexia nervosa, Peter Jackson J discussed E's behavior following her second directive, notwithstanding that she had already been found to lack capacity. ${ }^{29}$ Given the lack of clarity, there is at least an arguable case that the actions of a person with dementia after losing capacity might invalidate the directive, though the law remains uncertain.

\section{B. Lack of specificity in advance directives}

Concerns about applicability are also exacerbated in dementia cases. Under s25(4) MCA a decision will be inapplicable if the treatment required is not that specified in the advance directive, ${ }^{30}$ or any circumstances specified in the directive are absent. As mentioned earlier, one of the key problems with advance directives is their vague and general phrasing ${ }^{31}$ which fails to provide healthcare professionals with sufficient information to determine: (i) when the directive is intended to be triggered; (ii) if this situation has arisen; and (iii) what the directive requires in response to this. Triplett et al for example, found that most directives drafted for those with dementia were decisions to refuse life-sustaining treatment if in a PVS, terminal condition or endstage condition, though usually the directives did not specifically state the specific treatments that were not wanted. ${ }^{32}$ They concluded that directives are not comprehensive enough to cover many frequently encountered scenarios, suggesting instead that checklists of several scenarios be presented to the patient so that likely scenarios could be prepared for.

This is particularly true given that in England and Wales there is no requirement that advance directives can only be made in respect of a condition that the person is already diagnosed with. ${ }^{33}$ While Triplett's study shows the generality with which

\footnotetext{
25 A. Ruck Keene, 'Advance decisions: getting it right?' (2012)

$<$ http://www.39essex.com/docs/articles/advance decisions paper ark december 2012.pdf $>$ at 27.2.

26 Included as an appendix to The Joint Committee on Human Rights 15th Report of is ${ }^{2}$ Pis Session 2004 05 (2005) <http://www.publications.parliament.uk/pa/ iscep.jit200405/jtselect/jtrights/97/9702.htm>

27 Mental Capacity Bill, Explanatory Notes (2004), para 85.

28 [2012] EWCOP 1639.

29 ibid, [69].

${ }^{30}$ MCA s25(4)(a).

31 Supra $\mathrm{n} 14$.

32 Supra 2.

${ }^{33}$ Other jurisdictions do impose such a restriction, for example in Victoria, Australia (Medical
} 
even those directives drafted with dementia specifically in mind can be drafted, many directives are drafted without any condition in mind at all, covering losses of capacity in a number of eventualities. The courts also struggle in this regard: in W Healthcare Trust $v H,{ }^{34}$ despite $\mathrm{H}$ saying that she did not "want to be kept alive by machines", Brooke L.J. concluded that this was not "sufficiently clear to amount to a direction that she preferred to be deprived of food and drink for a period of time which would lead to her death in all circumstances." Despite attempts post-Aintree to give more weight to the wishes and feelings of people lacking capacity when making treatment and care decisions, ${ }^{35}$ evidence of their wishes is frequently vague and inconsistent, failing to give clear guidance of what they would want in the particular circumstances now under consideration. There is therefore insufficient detail to be able to give clarity about when the decision was intended to apply, and therefore to determine whether, under s25, it was applicable.

\section{The degree of foresight required}

Under s25(4)(c), an advance directive may also be inapplicable if there are reasonable grounds to believe that circumstances exist which the person had not anticipated at the time of drafting the directive and which would have affected his decision. While this may cover some of the epistemic concerns raised above about the lack of information available to people when drafting directives, it again suffers from ambiguity in the context of dementia. Research has frequently shown that while people are often gripped with terror at the prospect of an existence with dementia, this is not a reality that afflicts all (or even most) people with dementia. While there is evidence that some people with dementia often report feelings of loss (of independence, dignity, friends, memories), which can lead to low self-esteem and depression, ${ }^{36}$ and with it the desire to end one's life, others have been found to live a perfectly peaceful and contented existence, ${ }^{37}$ indicating that anticipating the impact of dementia is incredibly difficult. Evidence also suggests a tendency for the competent person to underestimate the quality of life of the incompetent. ${ }^{38}$ While contemplating existence with a physical impairment is hard, ${ }^{39}$ understanding the impact of cognitive decline is even more difficult, such that to some extent all advance directives in the dementia context may fail sufficiently to "anticipate" everything which would have affected the decision, and thus be inapplicable. This issue of applicability is clearly confounded by the issues that plague all advance directives, namely that the therapeutic options may change considerably, as might the values and priorities of the person drafting the

Treatment Act 1988 (Vic)).

34 [2005] 1 WLR 834.

35 See A. Ruck Keene and C. Auckland, 'More presumptions please? Wishes, feelings and best interests decision-making' (2015) 3 Elder Law Journal 293.

${ }^{36}$ N. Aggarwal et al, 'People with dementia and their relatives: personal experience of Alzheimer's and of the provision of care' (2003) Journal of Psychiatric and Mental Health Nursing 10(2) 187-197.

${ }^{37}$ D. Gilbert, Stumbling on Happiness (Vintage, 2005), at p 1-15

38 A. Asch, 'Distracted by Disability' (1998) 7 Cambridge Quarterly of Healthcare Ethics 77. 'í']

${ }^{39}$ L.C. Vogel et al, 'Long-term Outcomes and Life Satisfaction of Adults Who Had Pediatric Spinal Cord Injuries' (1998) 79 Archives of Physical Medicine and Rehabilitation, 1496. 
directive. It is difficult to know therefore, what degree of 'anticipation' or foresight is demanded by the statute, especially in the context of dementia.

\section{Lack of contemporaneous capacity assessment}

As Jonathan Herring and Jesse Wall observe, legal capacity 'typically seeks to determine the minimum necessary for autonomy and treats the person as autonomous once they cross that threshold. ${ }^{40}$ If an advance decision is to be autonomous, its author must therefore at the very least be demonstrated to have capacity.

Under section 2(1) MCA, 'a person lacks capacity in relation to a matter if at the material time he is unable to make a decision for himself in relation to the matter because of an impairment of, or a disturbance in the functioning of, the mind or brain.' Section 3(1) further explains that: 'for the purposes of section 2, a person is unable to make a decision for himself if he is unable-

(a) to understand the information relevant to the decision,

(b) to retain that information,

(c) to use or weigh that information as part of the process of making the decision, or

(d) to communicate his decision (whether by talking, using sign language or any other means).'

An essential part of the capacity assessment is therefore determining that the person understands (and can retain and use) the information relevant to the decision. According to the Code of Practice, the relevant information for making a decision includes: the nature of the decision, the reason why the decision is needed, and the likely effects of deciding one way or another, or making no decision at all. ${ }^{41}$ The test for capacity therefore mirrors the minimalist conception of autonomy articulated above.

The MCA rightly limits the creation of directives to people with capacity, over $18,{ }^{42}$ and the accompanying Code of Practice goes further: "it is important to be able to establish that the person making the advance decision.... had the capacity to make that decision when they made it". ${ }^{43}$ Yet despite Willmott's contention that "it is axiomatic that only a competent individual should be able to complete an advance directive,"44 nothing is required by way of a contemporaneous assessment of capacity or documentation to this effect.

\footnotetext{
40 J. Herring and J. Wall, 'Autonomy, capacity and vulnerable adults: filling the gaps in the Mental Capacity Act'(2015) Legal Studies 35(4), 698-719, 702.

${ }^{41}$ Department for Constitutional Affairs, Mental Capacity Act 2005 Code of Practice (London: TSO, 2007), 4.16

42 MCA, s24.

${ }^{43}$ Supra $\mathrm{n} 41, \mathrm{~s} 9.8$.

${ }^{44}$ L. Willmott, 'Advance Directives and the promotion of autonomy: A comparative Australian statutory analysis'(2010) 17 JLM 556, 566.
} 
As with the rest of the MCA, ${ }^{45}$ a presumption exists in favour of finding capacity "unless they are aware of reasonable grounds to doubt the person had the capacity to make the advance decision at the time they made it". ${ }^{46}$ Despite Munby J's dicta in $H E$ $v$ A Hospital Trust that doubts should always be resolved in favour of the person having capacity however, ${ }^{47}$ concerns have resulted in invalidating directives. In $A$ Local Authority $v E,{ }^{48}$ an advance directive was deemed invalid notwithstanding that it complied with the relevant formalities, appeared to be clearly applicable, and $\mathrm{E}$ had been advised both by her Independent Mental Health Advocate and solicitor that she had capacity to write it. E was a 32 year-old woman with severe anorexia nervosa, who had written a directive to the effect that if she was close to death, she did not want tube feeding or life support. The words of Peter Jackson J are telling:

"Against such an alerting background, a full, reasoned and contemporaneous assessment evidencing mental capacity to make such a momentous decision would in my view be necessary. No such assessment occurred in E's case and I think it at best doubtful that a thorough investigation at the time would have reached the conclusion that she had capacity." 49

In the absence of a well-documented contemporaneous capacity assessment therefore, it is difficult to feel confident that the decision being made is at least minimally autonomous and carries the resulting moral authority.

\section{E. Conclusion}

Given the difficulties in applying these provisions in the context of dementia, the immunity from liability for doctors who fail to uphold directives clearly provides considerable discretion for doctors not to comply with directives in circumstances when they are not satisfied that it is valid or applicable. This flexibility is essential. As Jonathan Herring argues, to deny someone beneficial treatment on the basis of a nonautonomous refusal can infringe their rights, and "have serious consequences for their long term welfare and ability to exercise their autonomy in other occasions". ${ }^{50}$ This is especially so where the treatment in question is life-sustaining. It is imperative therefore that doctors have a mechanism by which they can choose not to follow a decision if they deem it to be non-autonomous or non-applicable to a given scenario. Rather than removing some of the doctor's discretion under s26 to override directives therefore, the focus should be instead on tightening the conditions surrounding the creation of directives so that clinicians feel more comfortable upholding them, and have more information available to them to allow them to make informed determinations over their validity and applicability. A framework must be created to

\footnotetext{
45 MCA, s1.

46 Supra n41, s9.8.

47 [2003] EWHC 1017, 415.

48 [2012] EWCOP 1639.

49 ibid, [65].

${ }^{50}$ J Herring, 'Peter Skegg and the Question No-One Asks: Why Presume Capacity?' in M Henaghan and J Wall (eds), Law, Ethics, and Medicine: Essays in Honour of Peter Skegg (Thomson Reuters 2016).
} 
give doctors clearer guidance on the information available to the person when they were drafting the directive, and when the advance directive was intended to apply, if they are to feel confident that they are following the clear and unequivocal wishes of the patient.

Even if efforts can be made to enhance the specificity of directives, there remains the problem of where the values and priorities that underpinned a directive have changed. While this is a problem inherent to making decisions in advance, steps can be taken to help clinicians identify those situations where this has occurred, thus providing them the necessary information to bring substance to the provisions in section $25 \mathrm{MCA}$.

\section{HOW CAN THE LAW BETTER SAFEGUARD AUTONOMY IN ADVANCE DIRECTIVES?}

Under the current legal regime, while the person making an advance directive must be competent, ${ }^{51}$ and the decision reached be valid and 'applicable' to the situation at hand, ${ }^{52}$ there are no safeguards in the Act designed to ensure that the person is in fact competent, informed, or free from undue influence when drafting the advance directive. In light of the difficulties in ensuring the autonomy of anticipatory decisions, this section will suggest amendments to the legal framework of advance directives, to provide greater safeguards aimed at ensuring that decisions are, when drafted, sufficiently autonomous.

The proposed changes will require doctors to play a central role in the drafting of directives, ensuring both that the person is competent and informed, and that the directive is drafted with sufficient specificity and clarity that it is easy to interpret and implement by the later doctor. In fact, evidence suggests that the lack of physician involvement could be affecting the implementation of directives. Although his research focused on the Netherlands, Vezzoni found doctors to have a low opinion of the effectiveness of advance directives, often choosing not to follow them where they conflicted with their medical judgment. ${ }^{53}$ The lack of compliance among doctors was attributed to their belief that the lack of physician involvement rendered them "of low medical quality", ${ }^{54}$ a view supported by the findings of Schiff et al who raised similar concerns that "so few geriatricians had been involved in the construction of living wills". ${ }^{55}$ More involvement by healthcare professionals in the drafting of directives might therefore make doctors feel more comfortable in upholding them.

\footnotetext{
${ }^{51}$ MCA, s24(1).

52 MCA, s25(1).

${ }^{53} \mathrm{C}$ Vezzoni, The Legal Status and Social Practice of Treatment Directives in the Netherlands (Groningen: RUG, 2005), cited in E Marike et al, 'Advance Directives in Dementia: issues of validity and effectiveness.' (2010) InternationalPsychogeriatrics 22:2, 201-208.

54 ibid, 205.

${ }^{55}$ R. Schiff et al, 'Living wills and the Mental Capacity Act: A postal questionnaire survey of UK geriatricians’ (2006) Age and Ageing 35:116-121, 119.
} 


\section{A. Greater Involvement of the Medical Profession}

Given the problems identified above concerning the lack of contemporaneous capacity assessment, it seems a well-documented contemporaneous capacity assessment is required if the directive is to be upheld, and though it need not be by a doctor, a medical opinion will indubitably carry greater 'clout' in both hospital and courtroom. In the absence of this assessment, it is difficult to have confidence that the decision was truly autonomous.

The effect of this would be to reverse the presumption of capacity that exists elsewhere in the MCA, at least in evidential terms. The desirability of a presumption of capacity outside of the context of advance directives has been questioned elsewhere, ${ }^{56}$ and it is not the intention of this paper to engage in that debate. In his seminal paper on the issue however, Peter Skegg quoted from Lord Donaldson in Re $T$, where he suggested that "doctors faced with a refusal of consent have to give very careful and detailed consideration to the patient's capacity to decide at the time when the decision was made". ${ }^{57}$ In a similar vein, the MCA Code of Practice is clear about the importance in carrying out an assessment of capacity wherever capacity is in doubt. ${ }^{58}$ While the comprehensiveness of this assessment may differ depending on the patient and circumstances, it certainly seems unlikely (and perhaps even negligent), notwithstanding the presumption of capacity, that a doctor would permit someone to make a contemporaneous refusal of life-sustaining treatment without clear evidence that the person understands the nature and consequences of the decision. As a doctor later called upon to implement a directive has no opportunity to assess whether the person would have had capacity, it would not therefore seem such a significant step to require clear evidence of a contemporaneous capacity assessment at the time of drafting the decision. Of course this would play more than just an evidential role reversing the presumption would also mean that if there were cases in which the person had an assessment but their capacity remained uncertain, the presumption would not operate to later render the decision enforceable. Given the clear harm of tying someone with dementia to a decision that is no longer deemed in their best interests however, it is difficult to justify upholding an advance directive where their capacity at the time of drafting was doubtful.

In order for an advance directive to be binding therefore, the person should have to be assessed to see if they meet the test for capacity under the MCA. Given the requirements of the test for capacity, a person making a decision would need to know their prognosis, understand the associated symptoms, and comprehend the consequences both of their illness, and of any treatment decision they make in relation to it. As discussed above, this presents two difficulties in respect of advance

\footnotetext{
56 Supra n49; PDG Skegg “Presuming Competence to Consent: Could Anything be Sillier?” (2011) 30 UQLJ 165.

${ }^{57} \operatorname{Re} T$ (Adult: Refusal of Treatment) [1993] Fam 95 at 113A. [is

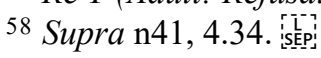


directives: firstly, how can it be ensured that a person fully understands the nature of the conditions (and treatments) included within their directive, particularly where their decision might relate to a range of conditions which they have not been diagnosed with and therefore have not had cause to fully consider? Secondly, there will undoubtedly be occasions where, owing to some medical advance, the prognosis of a condition has altered significantly since the directive was made. Does this render the original decision invalid? Both of these go to the question of whether the advance directive was sufficiently autonomous.

In the latter case, we clearly cannot be justified in upholding the directive, given that it was made with no real understanding of the nature and consequences of the decision. This situation would be captured in the provision in s25(4)(c) MCA discussed above, and so the doctor would not be liable for overriding it.

More difficult is the first concern raised, that directives may be made without sufficient information or understanding of either the potential future condition, or the treatment options. There is currently no legal requirement that any discussion with a healthcare professional need take place, notwithstanding that the Law Commission noted prior to the legislation, that a decision "made independently of any discussion with a healthcare professional might often be based on erroneous ideas and information". 59

Perhaps as a result of the lack of legislation, various informal attempts have been made to ensure that individuals gain the requisite information. The Alzheimer's Society in its Factsheet on Advance Decisions recommends a discussion with a GP, who can provide "information on how your illness is likely to affect you as it progresses", and help you "understand the advantages and disadvantages of choosing or refusing medical procedures in advance." ${ }^{60}$ The Alzheimer's Association too, in their End of Life Decisions Guide, has set out information about various treatment options which may become relevant in the later stages of Alzheimer's, including respirators, feeding tubes, antibiotics and DNACPR orders, as well as palliative and hospice care. ${ }^{61}$

While these measures are important, they do not obviate the need to consider a statutory requirement. Interestingly, many Canadian territories ${ }^{62}$ and Australian states $^{63}$ also do not make receipt of medical information a prerequisite for the validity

\footnotetext{
${ }^{59}$ Law Commission, Mental Incapacity, Law Com No 231 (HMSO, 1995), 5.30.

${ }^{60}$ Alzheimer's Society, Factsheet 463LP, Advance Decisions and Advance Statement, November 2014, available at $<$ http://www.alzheimers.org.uk/site/scripts/download info.php?fileID=2659>, 6 .

${ }^{61}$ Alzheimer's Association, 'End of life decisions: Honoring the wishes of a person with Alzheimer's disease' (2014), < https://www.alz.org/national/documents/brochure_endoflifedecisions.pdf>, 5.

62 E.g. British Columbia (Health Care (Consent) and Care Facility (Ādmission) Act, RSBC 1996, c 181), Saskatchewan (Health Care Directives and Substitute Health Care Decision Maker Act (Sask.) S.S. 1997, c. H-0.001, ss. 15-16), Alberta (Personal Directives Act, RSA 2000, c P-6) etc.

63 E.g. South Australia (Consent to Medical Treatment and Palliative Care Act 1995 (SA)); Australian
} 
of a directive, and in Western Australia, although advice is "encouraged", it is not obligatory. ${ }^{64}$ In fact, imposing such a requirement is rare. In Victoria, for example, following concerns by Victoria's Social Development Committee that advance directives "appear to involve an uninformed refusal of treatment in a wide range of unforeseeable circumstances" ${ }^{65}$ a requirement was introduced that medical information must be provided before the directive can be witnessed, the witness attesting to the fact that the individual has received the information and understood it. ${ }^{66}$ In Austria meanwhile, medical (and legal) advice is mandatory, requiring doctors to inform patients about the nature and consequences of the directive, as well as any alternatives, and to certify that the patient has correctly understood the advice. ${ }^{67}$ Similarly in Hungary, a directive must be accompanied by a written statement made by a board-certified psychiatrist indicating that the person made the decision in full awareness of its consequences. ${ }^{68}$ In the absence of such a discussion with a healthcare professional, it is difficult to be sure that the decision reached meets even the most basic requirements of an autonomous decision: that it is competent and informed, made in full contemplation and understanding of the nature and consequences of the decision. Doctors should play a vital role in the drafting of directives: testing the patient's understanding of the information presented to them, correcting any misinformation, directing the person to how they might respond to different eventualities, and discussing why they have chosen as they have. These may all be ways of also arriving at decisions which will better reflect their essential values, thus promoting even a more demanding conception of autonomy.

Caring for someone with dementia places a huge burden, both financial and emotional, on the person's family. Clinicians, when satisfying themselves that a person has given freely informed and capacitious consent to a directive, must also be confident that it is not the result of familial (or other) pressure. There is no straightforward way of assessing this, not least since directives are often intended by the author precisely to spare their loved ones the burden of care or making difficult decisions on their behalf. ${ }^{69}$ Nonetheless, where a doctor has real concerns about this, he cannot attest to the patient having given a competent and informed refusal.

\footnotetext{
Capital Territory (Medical Treatment (Health Directions) Act 2006 (ACT)); the Northern Territory (Natural Death Act 1989 (NT)) and Queensland (Powers of Attorney Act 1998 (Qld)). Medical Treatment Act 1988 (Vic), s5(1)(c) requires information to be given about the condition to the extent which is reasonably sufficient to enable the patient to make a decision about whether or not to refuse medical treatment.

67 Patientenverfügungs-Gesetz (2006)- full text (translated) available at:

$<$ http://www.patientenanwalt.com/english-documents/legal-information.html $>$.

${ }^{68}$ Health Care Act of 1997 (Hungary), Art 22.3.

${ }^{69}$ Black et al. 'Surrogate decision-makers' understanding of dementia patients' prior wishes for end-oflife care' (2009) Journal of Aging and Health 21:627-650.
} 


\section{B. Introducing formality requirements}

It has been argued above that a concern, both from an ethical perspective and in terms of applying the legal framework, is that directives are often drafted with insufficient detail to discern what the person's decision was in relation to a given set of circumstances. Clearly upholding an advance decision cannot be respecting a person's autonomy if the decision is applied in circumstances that were not anticipated or intended by the author to be captured. Mechanisms to enhance the focus and specificity of advance directives may therefore give more guidance to clinicians on the circumstances in which the directive was intended to apply, and what the author desired in response. They may also provide evidence by which to determine when there has been a radical change in the values and priorities of the author such that a directive, even when informed and autonomous at the time of drafting, may no longer represent their wishes.

One way in which more focus might be achieved is through the introduction of formalities. Currently, these are only required if the decision is to refuse lifesustaining treatment, ${ }^{70}$ unlike many other jurisdictions (for example across all of Australia and Canada) where formalities attach to all directives. This was a very deliberate decision by the Law Commission: '[a]lthough we gave careful consideration to the introduction of statutory requirements prescribing the form and contents of any advance refusal, we conclude that these would benefit no-one. ${ }^{71}$ Given the potential this leaves for vague and ambiguous decisions, or throwaway comments, to become binding on a person, strong justification must be proferred for this policy choice. Yet justification is severely lacking. As Maclean asserts, that the previous common law focused on the nature of the decision and not the way it had been recorded does not justify keeping the law that way. ${ }^{72}$ At the very least, directives should be written down, signed, and dated, a view supported by The Joint Committee on Human Rights who stated, "it is not clear to us why advance directives should not carry the additional safeguard that they should be required to be in writing."73

While the advance directives of most dementia patients currently concern lifesustaining treatment ${ }^{74}$ (not exclusively: many relate to Electric Convulsive Therapy), formalities should nevertheless apply throughout. Written instructions tend to be more specific and give a clearer sense of the breadth of the decision, while the formality of writing often has a channeling affect, ensuring the person is aware that they are making a legally binding decision, and perhaps causing them to think harder about it as a result. At the very least, a written directive provides evidence of its content beyond mere 'hearsay', thus potentially giving the healthcare professional "more

\footnotetext{
70 MCA, s25(5).

${ }^{71}$ Supra n59, 5.29.

72 A. Maclean, 'Advance Directives and the rocky waters of anticipatory decision-making' (2008) 16

Med L Rev 1, 11.

73 Joint Committee on Human Rights, Twenty Third Report of 2003-04, para 2.46. $<$ www.publications.parliament.uk/pa/jt200304/jtselect/jtrights/ 210/21004.html>.

74 Supra 2.
} 
confidence in the authenticity and currency" of the directive. ${ }^{75}$ It is noticeable that Lasting Powers of Attorney must follow a prescribed form, including being signed, witnessed and dated, notwithstanding the fact that an LPA must always act in the best interests of the incapacitated person. Given a directive may be contrary to the person's best interests therefore, at least the same degree of formality might be expected.

One of the Government's fears was that requiring formalities to create directives would necessitate formalities for their revocation, making it excessively onerous for people to change their mind. ${ }^{76}$ Certainly there is a risk that formalities could serve to frustrate the autonomy of those who reassess, tying them to an out-dated decision. While an informal revocation process could (and indeed does in the context of lifesustaining advance directives) exist alongside a formal process of creation, concerns may be raised over whether 'hearsay' evidence that they reneged will outweigh a clear written expression of their will. Of course it remains at the doctor's discretion to decide whether such actions constitute behaviour 'inconsistent with the decision' ${ }^{77}$ and it seems likely that where there is clear evidence of a change of heart, this will be taken seriously. Where there is ambiguity, it is better that the previously-binding advance decision is given some weight by becoming part of the evidence adduced in the 'best interests assessment', than risk undermining their autonomy altogether by tying them to an outdated decision that no longer reflects their values and priorities.

Dating clearly evidences how recently those views have been expressed and thus how likely they are to still remain current. This does not mean that a directive written a long time ago should not be considered binding, but merely that given the risks associated with the person's values and priorities changing, an up-to-date document is more likely to be an accurate reflection of the person's intention, and therefore the clinician can feel more confident in upholding it. Certainly the case law suggests as much: in X Primary Care Trust $v X B,{ }^{78}$ much emphasis was placed on the fact that the doctor regularly reviewed the directive to check whether it still reflected his wishes, while in $\operatorname{Re} A K$, the recentness of the decision was paramount. ${ }^{79}$ Although there is currently no review requirement on the face of the Act, the Code of Practice is clear that they should be reviewed regularly, and that "[d]ecisions made a long time ago are not automatically invalid or inapplicable, but they may raise doubts". ${ }^{80}$

\footnotetext{
75 Supra n44 568.

76 The Government's Response to the Scrutiny Committee's Report on the Draft Mental Incapacity Bill (2004) <http://webarchive.nationalarchives.gov.uk/+/http://www.dca.gov.uk/pubs/reports/mentalincapacity.htm>.

77 MCA, s25(2).

78 [2012] EWHC 1390 (Fam).

79 [2001] 1 FLR 129, [unknown].

80 Supra n41 9.29.
} 
Of course formalities inevitably erode some of the flexibility involved in creating advance directives. Yet as $W$ Healthcare Trust $v H$ illustrates, ${ }^{81}$ oral advance directives are often not sufficiently detailed to be applicable anyway, with doctors understandably reluctant to be bound by what may seem a throwaway comment made many years previously. Far from being an obstacle, the validation conferred by formalities could actually help clinicians in implementing directives.

\section{Introducing a proforma}

Even written directives can be unhelpfully vague however, with few people going beyond rejecting 'life-sustaining treatment' to consider specific treatments they might accept in the vicinity of death. This makes it difficult to know whether the circumstances in question had been contemplated by the person at the time of drafting, and therefore whether the decision has been made with full understanding of the nature and consequences of the specific choice they are now facing. One means of overcoming this would be to introduce a proforma, in which directives might record precise instructions in a range of likely scenarios. Certainly all jurisdictions in Australia except Queensland require that the directive, if made in writing, adheres to a prescribed form, ${ }^{82}$ and Willmott is positive about its impact on "encourag[ing] individuals to think carefully about their wishes regarding treatment, and to translate those wishes into specific instructions." 83 Schiff et al also found that two-thirds of the geriatricians interviewed felt that a proforma specifically designed for the elderly would be useful. ${ }^{84}$

The difficulty lies in designing a form sufficiently detailed to offer real assistance to the clinician, yet general enough to be capable of covering a range of conditions. In fact, Australia's statutory proformas, arguably fail to achieve this. In Western Australia for example, the form merely states that,

In the following circumstances:

I consent/refuse consent (cross out and initial one of these) to the following treatment: 85

This is similar to the proforma found in Southern Australia. ${ }^{86}$ In both, it falls to the patient to supply both the triggering events, and a list of treatments they will refuse,

\footnotetext{
81 Supra $\mathrm{n} 34$.

${ }^{82}$ Consent to Medical Treatment and Palliative Care Act 1995 (SA), s7(2); Guardianship and Administration Act 1990 (WA), s110Q(1)(a); Medical Treatment Act 1988 (Vic), s5(2); Medical Treatment (Health Directions) Act 2006 (ACT), ss8 and 21, Approved Form 2007 No 55; Natural Death Act 1989 (NT), s4(1).

${ }^{83}$ Supra $44,568$.

${ }^{84}$ Supra $\mathrm{n} 55,117$.

85 Accessible at $<$ http://www.health.wa.gov.au/docreg/education/population/HP11536_advance_health_directive_for m.pdf $>$

${ }^{86}$ Accessible at $<$ http://www.advancecaredirectives.sa.gov.au/upload/home/ACDFormSAMPLEsecure.pdf $>$.
} 
retaining a considerable degree of ambiguity. Even that designed by the Alzheimer's Society with dementia specifically in mind, leaves it to the individual to specify what types of 'life-sustaining' medical interventions they would find unacceptable, ${ }^{87}$ and though that of Compassion in Dying offers significantly more detail regarding triggering circumstances, it again does not list specific life-sustaining treatments. ${ }^{88}$ As people will not necessarily anticipate all the different treatments that might fall within the broad term 'life-sustaining', it is helpful if the proforma can give some direction as to the sorts of treatments that can arise, including ventilation, defibrillation, artificial nutrition or hydration, or in some circumstances, something as minor as antibiotics. This will help to ensure that the person gives proper consideration to what they would want in a range of likely scenarios.

Certainly proformas have the potential to be useful. The directive provided by Compassion in Dying, like that in Southern Australia, allows the individual to also state more generally their wishes, feelings and values, which both aids in interpreting the directive (and determining whether the original decision was autonomous in a more demanding sense), and may also help to determine what is in their best interests in circumstances which fall outside of it. Alzheimer Europe, in their Position Report, encourage people to write "statements of value" precisely because of "difficulties in obtaining an appropriate level of precision (which is neither too vague nor too specific to be of practical use)" ${ }^{89}$ Providing the doctor with information as to the values underpinning the decision may also help them to identify those situations where the values are no longer relevant to the person, thus raising questions over whether the directive ought to still be upheld.

Proformas relating to specific conditions may also be of particular utility to a clinician. Where the disease is degenerative like dementia, given the range of problems that may emerge at different stages, it may be useful to have a proforma which directs the patient to the sorts of decisions and treatments they might encounter during the development of the illness, as the Alzheimer's Association endeavours to do in their End of Life Decisions Guide. ${ }^{90}$ This could help to overcome some of the epistemic problems identified earlier, that people face an informational gap when making decisions in advance which can undermine the extent to which they may be considered autonomous. In fact, one problem with adopting a general statutory proforma is precisely that the condition-specific ones, which have the most potential to assist clinicians, would become obsolete. Thus rather than enhancing the information available to clinicians, they could serve to reduce it. While you could build in 'plug-ins' requiring you to complete a condition-specific proforma in some

\footnotetext{
${ }^{87}$ Accessible at < http://www.alzheimers.org.uk/site/scripts/download_info.php?fileID=2659>. accessed $4^{\text {th }}$ July.

${ }^{88}$ Compassion in Dying, Advance Decision Pack, accessible at $<$ http://compassionindying.org.uk/library/advance-decision-pack/> accessed $16^{\text {th }}$ July.

${ }^{89}$ Alzheimer Europe, 'Position Paper on the Use of Advance Directives' (2009) $<$ http://www.alzheimer-europe.org/Policy-in-Practice2/Our-opinion-on/Advance-directives $>$ Executive Summary, point (d).

90 Supra n61.
} 
cases, as it is unlikely that a person would complete such a proforma without having first been diagnosed with that condition, this may be tantamount in practice to introducing a 'current condition requirement', which would be problematic in the context of dementia, where many people have already lost legal capacity by the time they are diagnosed. ${ }^{91}$

\section{A non-statutory proforma}

Even if it may be overly restrictive to statutorily require proformas, it is clear that they could serve a useful function if carefully drafted. Perhaps therefore the solution is somewhere between legislation and policy. A directive should (in order to be legally binding), be in written form, dated, and signed by both the individual and the doctor (attesting to the fact that the person is competent, informed, and free from undue influence). Though it should not be mandatory, it should also be encouraged that the directive includes certain information designed to help the implementing physician to interpret the directive. This information may include the following:

1. Details of when the advance directive should be triggered;

2. Details of the treatments that the advance directive is intended to apply to;

3. Details of any treatments which the advance directive is explicitly not intended to apply to;

4. A statement of values, detailing the wishes or priorities underpinning the decision;

5. Details of any future events which might affect the applicability of the advance directive, for example pregnancy, children, marriage, or other value changes.

A proforma should be designed that meets these standards, and should be easily accessible both online (for example on the NHS and Gov.uk websites), and in GP surgeries. Once completed, the doctor may then assess the person's understanding of the things included within the directive and their capacity, and, based on a discussion with them about the reasoning behind the directive, suggest changes or other things to include or exclude from its remit. The doctor may also make suggestions on measures to improve the specificity and interpretation of it, if deemed necessary. This 'standard' proforma may also help by acting as a springboard to discussions between doctor and patient, and direct the patient's mind to certain issues which will enable them to formulate a directive that best reflects their values and priorities.

Where a person writes a directive which does not use the standard form, the doctor, when attesting to their capacity, will have the opportunity to read and discuss the directive with the person, and suggest ways in which it might be may be better drafted. A person should not have to follow the suggestions given by the doctor, but if they fail to do so, they should be made aware that there is an increased risk that the directive will either fail to be implemented by doctors (if it is too vague or ambiguous), or will tie them to decisions that they hadn't intended it to apply to. In

${ }^{91} \mathrm{~S}$. Fazel et al, 'Assessment of competence to complete ADs: validation of a patient-centred approach' (1999) BMJ, 318, 493-497. 
this sense, the role of the doctor is similar to that of a solicitor in the drafting of a will, guiding and questioning the person to ensure that the document produced reflects what it is that they want to achieve. Like drafting a will, a person can, if they prefer, choose to do it themselves, without either legal advice or a proforma, and this may be effective. However if the person wants to ensure there are no complications in the implementation of it, they are advised to follow legal advice. Adopting this method would help to ensure that the advance directive was competent and informed, as well as enhancing the specificity and applicability of the directive.

\section{E. Ensuring Advance Directives are Known to Clinicians}

The safeguards above will help improve the robustness of advance directives, and ensure that we can be more confident in the authenticity and relevancy of the decision. However there remains however a further problem - to ensure that the autonomous wishes of an individual are not frustrated, the directive must come to the attention of the treating clinician at the relevant time. This is especially problematic given the lack of formalities that currently pertain to making a binding directive: an oral declaration to a friend or an instruction scribbled on a piece of paper and placed in a drawer for many years can be sufficient to constitute a directive - it is likely that many directives therefore never come to the attention of the physician at all. For those with dementia that is sufficiently advanced to render them incapacitated, it is further doubtful that we can always rely on them to bring to the doctor's attention its existence, content, or location.

Many jurisdictions have adopted a national registry for advance directives. Spanish law for example, provides for the creation of a National Registry for directives, with each Autonomous Region having an official registry where citizens can register their directives, ${ }^{92}$ while many US States have enacted statutes that establish such a registry. ${ }^{93}$ In addition to the statutory registries, seven private national registries also exist, such as the "U.S. Living Will Registry" and "DocuBank", which store advance directives in an online database accessible by all healthcare providers. ${ }^{94}$ In the UK, the Organ Donor Register provides a useful model, while the establishment of national registers of directives across Europe has been urged by the Alzheimer's Europe in their 'Guiding Principles'. 95

Given the problems in accessing directives, "having a secure repository where advance directives can quickly and easy be retrieved by healthcare providers or

\footnotetext{
92 Law no. 41/2002 on Patient's Autonomy and on the Rights and Obligations Concerning Health Information (Spain), Article11.

93 eg Ariz. Rev. Stat. Ann. §36-3291; Idaho Code Ann. §39-4515; also see n159 and n160.

94 Accessible at $<$ https://www.uslivingwillregistry.com>.

95 Supra $\mathrm{n} 74,16(\mathrm{~d})$.
} 
named proxies" seems, as Allison Hughes observes, "like an obvious solution."96 (With the caveat that there is as yet insufficient evidence to establish how effectively the US system is working. ${ }^{97}$ ) It may also exercise a cautionary function: knowing it will be a matter of public record, and less easy to amend than a piece of paper in a desk drawer, might make the writer think more carefully before registering an advance directive.

Even the simplest idea is not without its complexities. In the US for example, the registries vary hugely over whether they are computerised, how they are funded, whether the directives are vetted for legal efficiency and who can access the record. While it may seem axiomatic that the registries should be maintained online (as in all US States except California and Louisiana ${ }^{98}$ ), and that directives should be vetted for their compliance with legal stipulations at registration, this inevitably comes at a price (in fact only Maryland and Montana are required by law to review advance directives ${ }^{99}$ ). While it is important not to create barriers by setting high fees for registering directives (LPAs in England provide a cautionary tale in this regard), with the public purse as stretched as it currently is in the UK, such a scheme may require some form of private funding.

A cheaper alternative might be to register all directives in people's medical records, as in Finland. ${ }^{100}$ If the recommendations above for making discussions with a medical professionals mandatory are accepted, it would not be a significant step for the directive to be added to the person's health records at the time of consultation. Indeed Hughes favours medical records over a registry precisely because of the focal role it gives to doctors. ${ }^{101}$ To be effective however, it would require the completion of integrated electronic health records, itself both timely and costly. Without this it is doubtful they could be sufficiently promptly accessible, especially given current problems with transferring GPs' notes. A national registry may therefore be advisable.

It would of course make revocation more difficult, but it is not clear that the barrier involved in going online to alter one's preferences is sufficiently grave to override the clear advantages of the system. Rather, it provides an easy means of ensuring that the advance directive always reflects the current wishes of the individual: with the US Living Will Register for example, participants are contacted annually to confirm that their wishes have not changed, and can log in at any time to amend or revoke a directive. Of course this comes with the risk that the person may revoke it at a time

\footnotetext{
${ }^{96}$ A. Hughes, 'State Advance Directive Registries: A Survey and Assessment' (2009) BIFOCAL Bar Associations in Focus on Aging and Law, Vol. 31(2), 36.

97 ibid, 43.

${ }^{98}$ La. Rev. Stat. Ann. §40:1299.58.3; Cal. Prob. Code $\S 4800-4806$.

${ }^{99}$ Md. Code Ann., Health— Gen. §5-619 to 626; Mont. Code Ann. §50-9-501 to 505.

${ }^{100}$ Act on the Status and Rights of Patients of 1992 (Finland), Article 8.

101 Supra $\mathrm{n} 82,36$.
} 
they lack capacity. If however a person feels sufficiently strongly that they do not want the directive to be determinative of their treatment, again it would surely be better to permit them to revoke it.

Perhaps more complicated is the issue of alterations. Clearly it would be at odds with the above discussion if a person could go online and amend their directive to refuse treatments in a wider range of circumstances (or to refuse a wider range of treatments) without any assessment of capacity or understanding. It could be built into the registry that you may amend the directive online to cover fewer treatments, but would require a further consultation if you wish to cover more treatments. If the person decides to proceed in making changes without this, this could be kept on record (similar to a codicil in a will) to be used as evidence in a best interests assessment, even if not legally binding.

In fact, the relatively few empirical studies in this area indicate that treatment preferences among those who have signed advance directives remain relatively stable. Danis et al, when examining patients' choices for life-sustaining treatment, found those with living wills had very stable preferences $(86 \%),{ }^{102}$ and while Ditto et al ultimately found a lack of preference stability, participants with directives did show far greater stability than those without. ${ }^{103}$ Though these findings should be treated with csome caution (the time frames were markedly shorter than the lifespan of most directives), this nonetheless indicates that those who have completed advance directives are likely to have put a high degree of thought into them, and it should not be assumed that time will necessarily affect their preferences. Revocation and alteration may not therefore be a problem that afflicts many advance directive users.

\section{EVALUATING THE FRAMEWORK}

Under the changes proposed, the role of the doctor would thus become paramount: they would be expected to discuss with the patient their precise intentions in relation to a range of scenarios, as well as the kinds of things that might affect that decision in the future. Of course enhancing the autonomy of the advance directive would not alleviate the second ethical problem identified above, of the person's values changing in the future. However it may help the doctor implementing the advance directive to know whether this has occurred, and therefore when the decision may no longer represent their values and priorities. Where the person explicitly states that they do not intend the directive to be binding in certain circumstances, on certain decisions, or following certain events or lifestyle changes, this clearly helps the clinician assess the scope and applicability of the directive. Even where the relevant situation does not fall within one of these situations however, the use of a statement of values might

102 M Danis et al, 'Stability of choices about life-sustaining treatments' (1994) Ann Intern Med 120: 567-73.

103 PH Ditto et al, 'Stability of older adults' preferences for life-sustaining medical treatment' (2003) Health Psychol 22: 605-15. 
help the clinician to discern whether the current circumstances are the sort anticipated and planned for by the person, and provide them with some evidence to determine whether these values have changed significantly since signing the directive. This will give substance to the provisions in s25 MCA that the directive is inapplicable where there are circumstances that the person did not anticipate which would have affected his decision. ${ }^{104}$

This suggestion would necessitate a radical shift in the law's treatment of advance directives, placing much greater demands on both the person wishing to create an advance directive, and the GP involved in its drafting. While such requirements are perfectly plausible, they would of course limit the circumstances in which directives can be created. Where previously they could be created informally at any time, this requires at the very least a visit to the doctor. Although concerns exist that this might privilege the wealthy and educated, who are more likely to be aware of, and know how to meet, the strict requirements laid out in this paper, it is not clear that directives create any greater problem in this regard than the drafting of wills, or even contracts. Those who place significant value on their prospective autonomy will take the necessary steps to ensure their directive is binding, including a discussion with a healthcare professional if necessary.

It is also important to note that rendering an advance directive invalid does not render it useless. In the absence of a binding directive (or LPA), decisions must be made in a patient's 'best interests', ${ }^{105}$ which requires the decision-maker to consider inter alia, 'the person's past and present wishes and feelings'. ${ }^{106}$ Therefore a directive, even if not binding, should provide an important means of determining such wishes. Increasingly this provision appears to be gaining weight in the best interests calculus $^{107}$ - even should the balance be tipped in favour of greater formality and procedural hurdles therefore, s4(6) MCA continues to provide a means of protecting people's prospective autonomy, and ensuring that their values and priorities underpin the decisions made for and about them.

Given this, it may be questioned whether we need to draw such a stark distinction between legally-binding directives, and the non-binding evidence of a person's past wishes that forms part of their best interests assessment. One might instead suggest that we look at all the evidence we have of a person's past views in the round (be that in written form or otherwise, informed or impromptu), to get a sense of what the person previously wanted, and feed this into our overall assessment of their best interests. This would permit a flexible approach to be maintained in difficult cases such as dementia, allowing evidence of their previous views to be balanced against

\footnotetext{
$104 \mathrm{MCA}, \mathrm{s} 25(4)(\mathrm{c})$.

$105 \mathrm{MCA}, \operatorname{ss} 1(5)$ and 4.

106 MCA, s4(6)(a).

107 Supra $\mathrm{n} 35$.
} 
other factors and information, to reach the decision that is deemed best for the individual in the circumstances.

While this might have the advantage of flexibility and sensitivity, it comes at great cost to the person's autonomy. In a best interests assessment, the person's wishes, even if a clear and thoughtful expression of their will, form just one part of the balance sheet. No one of the factors set out in section 4 is, on the face of the statute, to take priority in the best interests assessment, thus while the person's past wishes may be an important part of the determination, they will 'not necessarily be the deciding factor'. ${ }^{108}$ A large degree of discretion is thus left to each decision-maker to decide on the weight to be accorded to them in the assessment, with the possibility that an individual's previous expressions of will may frequently be outweighed by other factors. Certainly the House of Lords, in its post-legislative scrutiny of the MCA, was critical of the way that these provisions had been implemented in practice, observing 'the empowering ethos of the Act has not been widely implemented' ${ }^{109}$ On the evidence reviewed, it found that the wishes, thoughts and feelings of the person lacking capacity were 'not routinely prioritised'. ${ }^{110}$ Instead, 'clinical judgments or resource-led decision-making predominate.' 111

An understandable reluctance among medical professionals to uphold the person's previous wishes where they appear not to be in his or her best interests may therefore result in little value being accorded to the person's autonomy and self-determination. Indeed the perceived importance of advance directives is precisely as a "means of preserving the autonomy of people with dementia and reflecting their human dignity". ${ }^{112}$ Thompson et al, for example, found that in nine of 12 interviews conducted with healthcare professionals, and in all the focus groups, participants highlighted the importance of the directive in safeguarding autonomy when individuals can no longer communicate their wishes. One comment was particularly telling:

"...it allows her to take responsibility for her own values...and for some people death isn't the worst thing so it allows her to say that 'this is my value judgement', albeit at one point in time but 'these things for me are worse than dying' and that's on record." 113

It is a truism that people often value things above life itself - relationships, dignity, religious values, or simply being free from pain. We have little difficulty accepting this in people who have capacity: their right to refuse treatment, even if it ends in

\footnotetext{
108 Supra n41, 5.38.

${ }^{109}$ House of Lords Select Committee on the Mental Capacity Act 2005, 'Mental Capacity Act 2005:

post-legislative scrutiny' (HL Paper 139, 13/3/14), 8.

110 ibid, 104.

111 ibid, 104.

112 Supra n89, Executive Summary, point 3.

113 T. Thompson et al, 'Health professionals' views on Advance Directives: a qualitative interdisciplinary study’ (2003) Palliat Med 17:403, 404.
} 
death, is enshrined both in our domestic ${ }^{114}$ and European law. ${ }^{115}$ But for a person to lose capacity does not mean that they are suddenly stripped of the essential values and preferences according to which they ordered their whole life, whether these be personal dignity, avoidance of pain, protection of loved ones, or religious obedience. When the contemporaneous exercise of autonomy is given such weight in medical practice, we must, as a matter of consistency, also accord respect to a person's prospective autonomy. As Lord Millett noted in Airedale NHS Trust v Bland, the right to self-determination is just as important "where the patient's refusal to give his consent has been expressed at an earlier date, before he became unconscious or otherwise incapable of communicating it..."116

While allowing a degree of flexibility for a doctor not to uphold those decisions he does not consider fully autonomous or applicable is important, to deny anyone the chance of making a legally-binding decision about how they wish the final days of their life to play out would be to encroach too far into the realm of individual choice. As Ronald Dworkin writes, 'making someone die in a way that others approve, but he believes a horrifying contradiction to his life, is a devastating, odious form of tyranny. ${ }^{117}$ Advance directives, when appropriately drafted, empower people to avoid this tyranny.

The effect of the proposed changes would be to mandate a much greater role for doctors, requiring them to act as 'gatekeepers' for the validity of advance directives. This will involve a reconceptualisation of the role of the doctor in end-of-life decisions, one which though desirable, and certainly timely, may nonetheless be uncomfortable for many healthcare professionals, especially given the time pressures already afflicting GPs. This involvement is however essential. Of course the move would have financial implications. While this is unavoidable, two observations should be borne in mind. Firstly, drafting directives is in fact relatively rare in the UK. A YouGov poll for Compassion in Dying in 2013 for example, indicated that only 4\% of people in the UK had directives. ${ }^{118}$ It may not therefore be a severe financial burden. Secondly, given the extensive costs of many forms of life-sustaining treatment, the significant savings that would follow from rejecting them would go some way towards offsetting the increased costs associated with the drafting of these refusals.

\section{CONCLUSION}

Currently advance directives are not subject to any form of scrutiny, and may be drawn up without any reference to the healthcare profession. Given that the moral authority of directives rests on them being an autonomous decision by the person, it is

\footnotetext{
${ }^{114}$ Re T (Adult: Refusal of Treatment) [1993] Fam, 95.

115 Y.F. v Turkey (2004) 39 EHRR 34, 33.

116 [1993] 2 WLR 316 (HL), 864.

117 R. Dworkin, Life's Dominion (HarperCollins, 1992), 217.

118 Accessible at < http://compassionindying.org.uk/wp-content/uploads/2014/11/YG-ArchiveCompassion-in-Dying-results-120913.pdf $>$ accessed $23^{\text {rd }}$ May 2015.
} 
difficult to justify upholding them in the absence of measures to ensure that they are autonomous at the time of drafting, and applicable in the event of implementation. Through capacity assessments and consultations, both clinicians and the courts will be given the reassurance they need to feel more comfortable about upholding such decisions. The involvement of the clinician in drafting the directive can help to ensure both that the person understands the nature and consequences of the decision that they are making, and that the directive is sufficiently specific to be capable of implementation. The greater level of detail that is likely to come out of these discussions, and the use of a proforma, will also provide doctors with the evidence needed to make an assessment about its applicability. While this may require significant changes to the legal framework surrounding advance directives, changes which will undoubtedly be timely and costly for both patient and doctor, it is difficult to justify upholding directives in the absence of this. 